\title{
The Potential of Bicultural Nikkeijin
}

\author{
Liang Morita ${ }^{1, *}$ \\ ${ }^{1}$ Graduate School of Languages and Cultures, Nagoya University, Furo-cho, Chikusa-ku, Nagoya 464-8601, Japan \\ *Correspondence: Graduate School of Languages and Cultures, Nagoya University, Furo-cho, Chikusa-ku, Nagoya \\ 464-8601, Japan
}

Received: January 5, 2017

Accepted: January 15, 2017 Online Published: January 25, 2017

doi:10.5430/sass.v4n1p21

URL: http://dx.doi.org/10.5430/sass.v4n1p21

\begin{abstract}
The Nikkeijin in Japan mostly work in unskilled positions in manufacturing, and due to unfavourable terms of employment, they have little chance of upward socio-economic mobility. Although many of their children do not perform well in Japanese schools and they drop out, some Nikkei children do continue their education and attend university in Japan. This paper focuses on the small minority who further their education but have received little attention in the literature. From interviews conducted with young Nikkeijin who are at university or have graduated from university, the author found that they are bicultural and bilingual (or trilingual, in Portuguese, Japanese and English). These talented young people have the potential to contribute to Japan in unique ways because of their language and cultural skills. The author argues that providing more support for the Nikkeijin's education will not only improve their socio-economic mobility, but also help to alleviate the deficiency of skilled workers caused by the rapid aging and decline of the Japanese population.
\end{abstract}

Keywords: Japan, Nikkei, bicultural, discrimination

\section{Introduction}

The Nikkeijin are descendants of Japanese emigrants to Latin America. They are the largest and most prominent group among Japan's recent immigrants. Many of them have come to Japan since 1990, when a long-term residence visa with no restrictions on employment was made available to them. In spite of their Japanese ancestry, they either speak little Japanese or none at all, and they are culturally Latin American. Most Nikkeijin work in dirty, dangerous and difficult jobs that the Japanese do not want, in the automobile and electronics industries. They play an important role in helping Japan maintain its competitiveness in these industries in the world. However, due to the unfavourable terms of their employment, the Nikkeijin are trapped in their working-class socio-economic positions with little chance of upward mobility.

Although some young Nikkeijin do go to school in Japan, many drop out and do not continue their education beyond junior high school. According to Green (2013), a very small minority of Nikkei teenagers further their education. Most studies on the Nikkeijin reiterate the fact that many young Nikkeijin drop out and discontinue their education, but the small number who do further their education has received little attention. The present paper addresses this gap.

This paper argues that just as the Chinese student migrants in Liu-Farrer's (2012, 2011) study who are highly educated, bilingual and bicultural have an occupational niche in Japan, Nikkeijin who are educated to a high level are also bilingual and bicultural, and have an occupational niche. Not only have they spent many years in the Japanese education system, these Nikkeijin are also experienced in part-time, low-wage employment. At their places of employment, they are exposed to spoken Japanese, Japanese cultural practices and they see for themselves how Japanese society functions.

The bicultural and bilingual (often trilingual, since many speak good English as well) skills of these Nikkeijin are valuable in many contexts, both business and non-business. One such context is in organisations, developing overseas business for Japanese firms in the Spanish- and Portuguese-speaking world. This view of bicultural Nikkeijin as valuable human resources is supported by research in social psychology as well as management. In social psychology, Leung and Chiu (2011) found that biculturals are effective intercultural communicators. In 
management, Brannen and Thomas (2010) found that biculturals are ideal integrators and mediators in organisations.

One way to help the Nikkeijin achieve socio-economic mobility would be to provide more support for their children's education so that more young Nikkeijin further their education beyond junior high school and high school. Based on what this paper presents, that bicultural Nikkeijin are in fact valuable human resources with great potential to contribute to Japan, there is more justification than ever for the country to invest in their education.

The next section describes the methodology used in conducting this research, which is followed by an account of the Nikkeijin in Japan (Section 3). The factors taken into consideration when Nikkei young people are applying for university and the reasons for continuing their education are discussed in Section 4. A discussion of an occupational niche for the Nikkeijin, being bilingual and bicultural, and findings about biculturals in social psychology and management, is presented in Section 5. Concluding remarks in Section 6 bring the paper to a close.

\section{Methodology}

Some parts of this study were conducted by using the documentary research method, with academic publications as the main source of documents. This method, which uses generates data by using documents from the past and present, has a longstanding history in the social sciences, and continues to evolve with hybrid and virtual documentary sources from the internet and email. (McCulloch, 2004) The basic categories of documents are personal, public and official (Hill, 1993), and academic publications fall under public documents, which typically comprise published and publicly presented documents.

The author initially visited the websites of major publishers of books and journals in the field of social sciences and performed searches using keywords such as Brazilian Japan and Nikkeijin Japan in order to search for relevant publications to use as data. The reference sections of publications retrieved in this manner were examined and the author noted down further relevant publications and included them in the data. Using this method, an extensive data was built.

It is widely-understood that in a documentary inquiry, the researcher must assess the documents before extracting content. Whenever possible, the author verified the facts, information and figures presented in the publications with primary sources such as government websites and publications. Only information and figures which have been confirmed in this manner are included in the present paper. The contents of the academic publications in the data were also cross-checked for consistency, and again only those which have passed the consistency test are presented here.

The author also conducted semi-structured interviews with nine Nikkeijin who completed high school or both high school and university in March and April 2016. She first contacted a few Nikkeijin undergraduates at a third-tier university in Aichi, and the rest of the interviewees were recruited using the snowballing method. Aichi is ideal for this study because of the large numbers of Nikkeijin who work in its significant automobile and electronic industries. Five interviewees attend the aforementioned university, three are graduates of the same university and one is a student at a senmon gakko ('post-secondary vocational institute'). Six of them are male and three, female, and they are aged between 19 and 23. Recruiting larger numbers of Nikkeijin who completed high school or university as interviewees proved challenging due to the fact that their numbers are small. As Green (2013:277) noted, 'A very small minority further their education. Many Brazilian teenagers are much more likely to be working, like their parents, in Japanese factories.' The interviews were conducted in Japanese or English, depending on which language the interviewee is more comfortable with. The recordings are then transcribed, coded and analysed thematically.

\section{The Nikkeijin in Japan}

The Nikkeijin constitute the largest and most prominent group among Japan's recent immigrants. They are descendants of Japanese emigrants to Latin America. Among the Nikkeijin who have come to Japan, the Brazilians are the largest group. There were 14,000 Nikkei Brazilians in Japan in 1989 and the number rose to 100,000 in 1991, 200,000 in 1996 and 316,000 in 2007. It fell during the economic crisis in 2008 as many of them lost their jobs and returned home. In 2013, there were 230,552 Brazilians in Japan. (Takenoshita, 2013; 2015) One reason why large numbers of second- and third-generation Nikkeijin have been coming to Japan is economic and political instability in Latin America, especially the economic crisis in Brazil in the $1980 \mathrm{~s}^{1}$, but they would not have been able to come to Japan without the revision to the Immigration Control and Refugee Recognition Act in 1990. A new visa category for second- and third-generation Nikkeijin was introduced with the revision. This new visa is a long-term residence visa 
which lasts three years and has no restrictions on employment. Nikkeijin with any qualifications may apply for this visa. It is renewable and there are no limits on the number of times of renewal. Spouses and dependants are also covered by this visa regardless of ethnic origin. Green (2010) observes that the movement of Nikkei Brazilians from Brazil to Japan is facilitated by a transnational labour recruitment system which originates in Brazil, where there is a large number of recruitment firms which work with their Japanese counterparts to arrange visas, flights and employment for a large fee.

The official justification for introducing the new Nikkeijin visa was that the Nikkeijin should be allowed to visit the country of their ancestors, meet with their family as well as work to pay for their travels. Researchers such as Vogt (2015) have argued that the real reason was the need for low-wage, unskilled workers in manufacturing, particularly the automobile and electronic industries. This manoeuvre has allowed the government to secure a large number of unskilled workers without contradicting the principle of prohibiting foreign unskilled labour. Due to the nature of their jobs, the Nikkeijin are concentrated in prefectures dominated by industry and manufacturing such as Aichi, Shizuoka, Kanagawa, Saitama and Gunma.

\subsection{The Nikkeijin's Employment}

In addition to having to take up the dirty, dangerous and difficult jobs that the Japanese shun and despise, the Nikkeijin's terms of employment are unstable and precarious. While some Nikkeijin are employed directly by manufacturers, many are employed by dispatch agencies. These dispatched workers are taken on by manufacturers when there is a surge in demand for the manufacturer's products, and they are let go when demand drops, which means they are highly vulnerable to economic fluctuations.

According to Chiavacci (2014), foreign workers, especially the Nikkeijin, have become indispensable to the functioning of important, core sectors of the economy. Foreign workers are structurally embedded in leading, renowned export industries such as the automobile and electronics industries. Since foreign workers can be taken on and let go easily depending on the demand for manufacturers' products, they allow a high degree of flexibility to be achieved in industrial production. In the 1990s, the requirement for flexibility in production and responsiveness to demand increased tremendously in many industrial sectors and was of crucial importance to success and competitiveness. In labour management, this increased flexibility was primarily achieved by relying on dispatched workers, who were mostly foreign. Foreign workers, especially the Nikkeijin, are a crucial group in this market for dispatched workers and the market developed and became of central importance in the 1990s. They are the most flexible workers who can be hired at dispatch agencies and are ready to work for only a few days as well as work overtime or night shifts at short notice. Ogawa (2011) points out that working for dispatch agencies puts the Nikkeijin at an extreme disadvantage because there are no prospects for pay increments or full-time employment.

Takenoshita, Chitose, Ikegami, and Ishikawa (2014) describe the labour market in Japan as being bifurcated into the standard and non-standard sectors. Stable employment characterised by lifetime employment, seniority earnings and union protection is offered in the standard sector only. Global economic competition in the late 1990s and 2000s forced employers to cut costs and manufacturers to be more flexible in production and this led to the rapid growth of the non-standard sector, where unskilled, menial jobs are highly concentrated. Jobs offered by dispatch agencies also fall under the non-standard sector and this type of employment is not covered by the protection offered by labour authorities. During this period, many Nikkei Brazilians were employed by dispatch agencies. Although some employers hired Brazilians directly, most manufacturers increasingly relied on dispatch agencies. Today, most Brazilians are employed by dispatch agencies. (Takenoshita, 2013) The Nikkeijin are prevented from entering the standard labour sector because they lack Japanese credentials, language skills and the Japanese see them as foreigners who will eventually return to their country of origin. Because of this lack of mobility, the Nikkeijin are disadvantaged and marginalised in the labour market and are highly vulnerable to economic fluctuations. (Takenoshita, 2015) Takenoshita (2013) emphasises that the difficulty experienced by the Nikkei Brazilians in achieving upward mobility is deeply rooted in the attitudes of the Japanese towards immigrants, in their reluctance to accept immigrants as legitimate members of society.

In Tsuda's (2011) analysis, the underdeveloped nature of the foreign labour market in recent countries of immigration such as Japan means that foreign workers are employed almost exclusively in low-level, unskilled and temporary jobs with very little potential for upward mobility. In other words, most foreign workers are confined to the lowest segment of the labour market. In Tsuda's Hamamatsu study, 91\% of the Nikkeijin were performing unskilled or semi-skilled jobs. Only 9\% were employed in higher paid, skilled or technical jobs. 


\subsection{Young Nikkeijin's Education}

The fact that Nikkei children do not perform well in Japanese schools has received attention from the media and researchers. Many researchers, including Hein (2012), have written about how Japan has lagged behind in educating the children of the Nikkeijin, which perpetuates the Nikkeijin's socio-economic disadvantage (Takenoshita, 2013) and hinders upward mobility. (Takenoshita et al, 2014) Another reason for their lack of mobility is discrimination, which will be discussed later. Although the first nine years of education (from elementary to junior high school) are compulsory, foreign children are under no legal obligation to attend school. Most school authorities do not actively seek out foreign children who have failed to show up at school and significant numbers of these children do not go to school. (Vaipae, 2001) In Japan, the usual difficulties faced by foreign children in an unfamiliar schooling environment are compounded by the writing system of the Japanese language, which consists of the hiragana and katakana scripts as well as kanji ('Chinese characters'). Nikkei children have had pronounced difficulties in recognising and writing the hundreds of kanji required in elementary school. Although some progress has been made in recent years in areas where large numbers of Nikkei children reside, there is still little language support for them in many public schools. According to Hein (2012), Japan has failed to offer comprehensive language courses or address school absenteeism. Many Nikkei children who neither succeeded to master their native language nor Japanese have felt lost and rootless in Japanese society.

Many Nikkei teenagers drop out of the Japanese school system, mostly due to struggles to maintain fluency and progression in the Japanese language. Junior high school is more academically challenging than elementary school; high school is approaching and students need to be more competent in written Japanese. Japanese high schools, which have been described as regimented, demanding and culturally alien, are known for being difficult to navigate, even for some Japanese children. (Green, 2013) Few Nikkei Brazilian students make it to high school, since public high school admissions are strictly based on grades and entrance examinations, which require linguistic adaptation or acculturation. (Takenoshita et al, 2014) Furthermore, Takenoshita (2013) found that the economic uncertainty faced by Brazilian parents discourages them from enrolling their children in high school. A very small minority of Nikkei teenagers further their education. Many are much more likely to be working, like their parents, in Japanese factories. (Green, 2013)

Many Nikkei Brazilians have taken matters into their own hands and established a large number of schools approved or sponsored by the Brazilian government ${ }^{2}$. However, these schools require contributions to their operation costs in the form of fees, which discourage Brazilian parents who are cash-strapped from sending their children there.

Takenoshita's study shows that Nikkei Brazilians enjoy little upward socio-economic mobility and they remain in their manufacturing jobs. Green (2010) found that many Brazilian teenagers abandon their education in Brazil to travel to Japan with their family and lured by attractive salaries in manufacturing (five to ten times more than what professionals in Brazil receive), they work instead of continue their education.

As for Nikkei Brazilian children who do go to school, they suffer from prejudice and discrimination at the hands of their peers and teachers in public schools. Many of them experience bullying. As one interviewee recounts:

'They, they just, they just didn’t accept me to play with them. They say like "Go away”. But at, at that time I didn't want to, to do many things. But also they, even if I didn't want to do anything they just said "Go away". Or like in the junior high school, they hid my things and also they, they, they was playing with my name, because my name is Morita. And then like, they, they just... and put some like baka ('stupid') Mori and some other things... Yeah, it's childish but at that time it was really like, really hurt me. And because of it, like I, I stop going to school for like one week...'

Some Nikkei children have tried to hide their backgrounds and behave as if they were Japanese to avoid being bullied. Bullying has forced many Nikkei children to drop out of school. (Takenoshita, 2014)

\subsection{Discrimination}

Adult Nikkeijin also suffer from discrimination and social-class prejudice in their daily life and at their workplace. As one interviewee recounts:

'About a year ago, my sister and I came back to Nagoya from Shizuoka. We usually walk from Fujigaoka to Kamiyashiro, but because we had a lot of luggage and my sister was tired, we thought of taking a taxi from Fujigaoka. It was raining and we wanted for a taxi with our umbrellas at the taxi stand. There were two people in front of us in the queue and one person behind us. A taxi came for the person ahead of us and another one came. When we were at the top of the queue, the taxi came, stopped, saw us, and then circled the taxi stand area and ended up at the person waiting behind us. He/She kind of said to the taxi driver "No, thank you", that my sister 
and I were ahead of him/her in the queue, but the older, male taxi driver took no notice at all. Eventually the person behind us said "Sorry about that" and got in the taxi. My sister and I were really surprised. I was really surprised that this was happening now. This is year 2016! ... In the end we just walked home.'

The Nikkeijin are associated with poor, low-status, backward and crime-ridden nation-states in Latin America. The Brazilians in Oda’s (2010: 785) study illustrate the point well:

'They [my Japanese co-workers] ask me all kinds of things. If there are any buildings in Brazil, if we lived in the jungle. And when you say that you lived in Sao Paulo, a city as big as Tokyo, they just don't believe it!'

'At the company [where I work] we had to assemble a piece and some guy said we should do it this way. But when I look at the drawings I could see he got all wrong. But he just took the drawings from my hands and ignored me. Why? Because I'm Brazilian! ... Because I'm from the third world!'

This image of Brazil as a third-world country is well-reported in other studies. (Tsuda, 2003) The Nikkeijin are also perceived as descendants of poor and uneducated Japanese of low social status who could not survive economically in Japan and had to emigrate. (Tsuda, 2009) The 'return' migration of second- and third-generation Nikkeijin doubles this prejudice because they are thought of as those who could not survive economically in Latin America either.

Most Nikkeijin are in fact well-educated, of middle-class background and worked as professionals or business owners in Latin America before leaving for Japan. They experience considerable declassing when they come to Japan as they inevitably take up manufacturing jobs that are of low social-class status. Although most Nikkeijin come to Japan psychologically prepared to take on these jobs and are willing to temporarily endure the loss in social status for the tremendous financial gain, many subjects in Tsuda's (2009) study spoke openly about the demeaning nature of their work and their feelings of damaged pride and even shame.

In addition to the social class prejudice described above, there is also considerable cultural prejudice against the Nikkeijin based on negative evaluations of their Latin American behaviour. (Tsuda, 2009) Due to the fact that they were born and raised in Latin America, most Nikkeijin either spoke little Japanese or did not speak it at all and were culturally Latin American. (Takenoshita, 2013) Tsuda’s (2009) Japanese interviewees thought little of the Nikkeijin's work ethic and ability, and saw them as lazy, slow, irresponsible and careless at work. Their Japanese neighbours complained about them being a disturbance because of the excessive noise they make.

The Nikkeijin also experience social marginalisation. Takenoshita (2013) found that many Nikkei Brazilians have no social contact with the Japanese because they do not speak Japanese well. They have significant difficulties in forming ties with the Japanese partly because of the language barrier and partly because of the social boundaries between host and migrant and Japanese prejudice and discrimination against foreigners. (Takenoshita, 2015) Due to the fact that the Nikkeijin do not speak Japanese very well and are culturally Latin American, they are treated as foreigners. Takenoshita goes so far as to say that the Nikkei Brazilians are segregated from the Japanese.

The Nikkeijin respond to their exclusion in Japan by withdrawing into their social groups as an act of self-segregation. (Tsuda, 2009) Most of them do not actively seek out relationships with the Japanese because the Japanese do not seek out relationships with them. Many of them think of themselves as short-term settlers who will return to their home countries after building up sufficient savings. As a result, they have little incentive to integrate into Japanese society or establish long-term, meaningful relationships with the Japanese. Despite their self-perceived temporary status, they have created very extensive communities in various parts of Japan which enable them to conduct their lives exclusively within their communities without interacting with the Japanese.

The Nikkeijin have not yet become part of Japanese society due to the lack of systematic effort to integrate them. Although several local governments and NGOs have provided programmes to facilitate integration, little has been done at the national level. (Takenoshita, 2013) The government's priority has clearly been immigration control and border enforcement. As far as foreigners are concerned, the authorities' agenda is usually about how to control them rather than how to integrate them. Public discussion has also focused on immigration control, and integration has been neglected. (Kibe, 2014) This is partly because of the discourse that associates foreigners with crime and partly because of the view that foreigners are only in Japan temporarily and will eventually go home. Although many Nikkeijin are target earners who will return to their home countries in the near future, a large proportion of them are settling long-term or permanently in Japan. (Tsuda, 2009) There is an urgent need for systematic integration measures at the national level. 


\section{The Nikkeijin in Universities}

When it comes to the education of the Nikkeijin, the vast majority of the literature refers to the challenges they face in the Japanese education system such as in reading and writing Japanese, and maintaining fluency and progression in the language. There are also frequent mentions of drop outs and failure to progress to high school, since public high school admissions are strictly based on grades and entrance examinations, which require linguistic adaptation or acculturation. (Takenoshita et al, 2014) The general verdict is that 'A very small minority of Nikkei teenagers further their education. Many are much more likely to be working, like their parents, in Japanese factories.' (Green, 2013)

There is a gap in the literature in that there have been very few studies conducted on the aforementioned 'very small minority' and little is known about these Nikkeijin who further their education. The current paper attempts to fill this gap.

Takenoshita et al's (2014) comment that public high school admissions are strictly based on grades and entrance examinations, which require linguistic adaptation or acculturation, applies not just to public high schools but also to public universities and top-ranking private universities. For the eight interviewees in the current study who attend or attended university, three factors were taken into consideration when they were deciding whether to apply for university and which university to apply for. The first is the availability of Administration Office (AO) admission, which is an alternative to traditional entrance examinations in which the administration office of a university considers an application based on grades achieved in high school and teachers' recommendations. AO admission is generally known to be less rigorous than entrance examinations admission. Seven out of eight of the interviewees gained admission via the $\mathrm{AO}$ route.

The admission requirements of public universities in the region where the interviewees went to university, Aichi, would consist of the Senta Shiken ('Centre Examinations') and entrance examinations for each public university, both conducted in the Japanese language. The Senta Shiken is a centralised set of examinations in several subjects administered throughout the country to high school students at the end of their high school education, usually at the end of January. Applicants to public universities need to perform well in both the Senta Shiken and public universities' entrance examinations (which usually take place at the end of February) offered in several subjects in order to gain admission. Many agree that these examinations are too difficult for Nikkei applicants.

The second factor Nikkei university applicants take into account is the availability of scholarships. Most Nikkei families cannot afford the fees charged by private universities, which reminds us of the stark reality that although most Nikkeijin are members of the middle class in Brazil and their Japanese salaries in manufacturing are five to ten times more than what Brazilian professionals earn, they cannot afford a private university education for their children in Japan. According to one interviewee, the university she attends offers full scholarships and half scholarships, and even half scholarships go a long way in alleviating Nikkei students' financial hardship. Nikkei parents who have tried to secure a bank loan for their children's education find themselves being turned away by Japanese banks because they are not Japanese:

'And to get into university was kind of hard, because... I passed, but the problem was the money. A lot of the loans, we went to the bank, they didn’t accept Nikkeijin. I don't know why... I mean, I don't know why. Still... I think we went to five banks... So I don't know what is the problem. Or maybe it's because the name, their nationality.'

Ironically, the interviewee above is the only interviewee who passed the entrance examinations for the university and was not counting on AO admission. She felt her parents were denied loans at banks because their names were written in katakana, the usual script used for foreigners' names, rather than the usual kanji for Japanese names. Most Nikkeijin have names which sound Japanese but are written in katakana, which marks them as foreigners. Her parents may also have been turned down because of their Brazilian nationality.

The third factor the interviewees took into account in their choice of university was the availability of study abroad programmes or more generally, opportunities to go abroad. One of the reasons they had chosen their university was the wide selection of study abroad, volunteer and internship programmes, all generously subsidised by the university. The university in question considers these programmes to be an important part of its internationalisation and its students' education. In the interviews, opportunities to go abroad were emphasised by the interviewees, and it seemed that they were taken seriously and had much appeal to the interviewees. In fact, three of them had been to London and Manchester on these programmes and they claimed to have benefitted tremendously from their experiences.

One of the questions in the interviews was what made the interviewees persevere in their education when dropping 
out seemed to be the norm among the Nikkeijin. 'Not giving up' was a frequent response, and in addition to that, parental support:

'One of them (the reasons why I continued my education) is my mother, because she, she was really, really like, forcing us to study, because... Especially me, because I'm, I'm lazy. I'm lazy, because I, I need to like... I'm, I'm really lazy to do the things I... But she was forcing me, especially when I was in the junior high and high school. Because at junior high I was, I didn't want to go to school because of some of bullying and other things then she was really angry with me. I had to go there, so this is one (reason).'

'There were many Nikkeijin around me who went to senmon gakko ('post-secondary vocational institute') or universities after high school, but because of money, dropped out to work. After I finished high school, I first went to senmon gakko before university. There was one time when I almost gave up too. But my parents insisted on me finishing university no matter what and told me money didn't matter so much. The will to continue studying and money are important, but just don't give up. Not giving up is the most important thing.'

From the second response, it is clear that money lures young Nikkeijin away from their education. This confirms Green's (2010) observation that many Brazilian teenagers abandon their education partly because they are lured by attractive salaries in manufacturing and they work instead of continue their education (see section entitled Young Nikkeijin's education).

Interestingly, the interviewee below presents an opposite point of view, that it was the avoidance of a life of working in factories, which she has some experience of, that kept her going in her university education:

'Well, as I told you, I didn't want the factory for my life. That's, that was the main key, because, you know? I see my parents, they're really good for me, they care about me. But I, I've been to a factory, I've worked in a factory and it's really depressing, it's even more depressing than even college, believe me. It's really awful. It's like, people are rude, it's dirty, it's, it's dangerous... I've worked in a, in a factory of electronics, and like my fingers, you know, the, the movement of my fingers? They, they were almost gone in, in just one month. And I imagine my parents that work for almost their entire life. So I didn't want that for me. I don't want this for, for my brother. And I, I don't want that for anybody. So that was main key, main key, that I decided to go to university. ... And I think that, that, that is also one of the reasons that I didn't drop out of... Decided to finish it.'

She continues to speak of dead-end manufacturing jobs that do not lead anywhere and limited socio-economic mobility below. These views echo those of Tsuda (2011) and Rocha (2014) on the socio-economic future of the Nikkeijin:

'I mean, because it's really easy, like to just quit high school and go to a factory. It's an, you, you, I mean it's an easy job. It's like easy to get but they don't think about it. And when they spend their, their whole lives, whole lives inside the factory then they will regret it. It's easy now but I think it's going to get difficult in the future. ... So maybe you never will be a Japanese, never grow your English, or like your abilities and skills or other things. You just, you just stagnate. Like you just stop and...'

The interviewee's point, which warns against short-sightedness in giving up one's education for manufacturing jobs, comes across clearly. A university education opens the door to many more opportunities in one's future but manufacturing jobs which may pay well now do not lead anywhere and keep the Nikkeijin in the same socio-economic position.

\section{Discussion}

\subsection{The Potential of Bicultural Nikkeijin}

The Nikkeijin may have been underestimated in their potential to serve and contribute to Japan. Partly due to prejudice, the Japanese in general have fixated on the role of the Nikkeijin as unskilled workers and little more. The Nikkeijin, especially those who are Japanese-educated to a high level, may have been overlooked. It is telling that Gabriel and Lucas (both pseudonyms) in this study have been hired and valued by their employers for being bicultural and trilingual (in Portuguese, Japanese and English). Gabriel has been working for a year in an estate agent's office in Anjo, a city in Aichi with many factories and a Nikkei presence. He is the person in his office who handles business with Nikkei clients as well as other foreign clients because of his language skills. Lucas has been hired by an American-based automobile dealership which has expanded its business to Japan, Australia, New Zealand and Thailand. At the time of the interview, he was about to start his job and he felt being Nikkei played to his advantage in securing the position. 
There are many advantages to hiring biculturals in firms. In research in management, Brannen and Thomas (2010) found that biculturals are ideal integrators and mediators in organisations. The authors point out that the success of today's complex organisations is based increasingly on the transfer and sharing of information, knowledge and practices of people-dependent technologies across organisational and cultural boundaries. Global business success depends increasingly on being effective in understanding and bridging between different cultures, and on being interculturally effective by integrating diverse cultural knowledge. Due to globalisation, more managers and professionals are required to interact with individuals from other cultures, make and maintain intercultural connections, work in culturally-mixed environments, and perform tasks with counterparts in different countries that require intercultural skills involving an understanding and sensitivity to different cultural perspectives. (Brannen, Garcia and Thomas, 2009) As collaboration, communication and trust-building become more important, and flows of knowledge and processes become critical success factors, the role of individuals in mediating between cultures is crucial to organisational success. Biculturals are ideal for this role.

At this point in the Discussion, it would be helpful to draw a comparison with the Chinese student migrants in Liu-Farrer's (2012, 2011) work in order to illustrate the present author's point about the Nikkeijin. Just as Liu-Farrer (2011) has shown in her work that Chinese student migrants who are highly educated, bilingual and bicultural have an occupational niche in Japan, Nikkeijin who are Japanese-educated to a high level also have a niche.

Liu-Farrer argues that education in Japan is a process of cultural immersion for Chinese students. Most of them take up part-time, low-wage jobs to support themselves, and these jobs constitute an important form of linguistic and cultural training. Through these jobs, Chinese students pick up the Japanese language, become familiar with Japanese cultural practices and gain an understanding of Japanese society. (Liu-Farrer, 2012) This view is supported by Ziguras and Law's (2006) work on international students in Australia and Malaysia. The authors found that cultural skills are acquired through extended exposure to the host society. They pointed out that international students are considered particularly desirable in Australia because of their familiarity with the local cultural and social environment, which they have gained through the years they spent in the Australian education system.

The occupational niche for Chinese student migrants consists of corporate positions in Japanese firms that deal specifically with businesses in China. (Liu-Farrer, 2011) These positions, which handle transnational production and marketing between Japan and China, require the bilingual and bicultural skills of Chinese student migrants. They make up are an increasingly important labour force in corporate Japan and are often sought to develop Japanese business in China. As business between Japan and China grows, so do employment opportunities for Chinese student migrants.

Nikkei young people who are Japanese-educated to a high level have spent many years in the Japanese education system. They are also experienced in part-time, low-wage employment. The interviewees in this study have taken up jobs in Uniqlo (a leading clothes retailer at the 'value' end of the market), Zara (Spanish-based clothes retailer), karaokes and factories. At their places of employment, Nikkei young people are also exposed to spoken Japanese, Japanese cultural practices and they see for themselves how Japanese society functions.

The bicultural and bilingual (usually trilingual, since many speak good English as well) skills of these Nikkeijin are valuable in both business and non-business contexts. Portuguese and Spanish are mutually intelligible, and when the list of Spanish-speaking countries is added to that of Portuguese-speaking countries, one realises that the Nikkeijin have the potential to play a large role in developing overseas business for Japanese firms in business contexts. We can see from Gabriel and Lucas' employment situations that some employers have started taking advantage of the skills of these Nikkeijin. Whether other employers can overcome their prejudice and move past the Nikkeijin-as-unskilled-worker stereotype remains to be seen. In non-business contexts, these Nikkeijin could serve as bridges or liaison between the Japanese and Nikkei community, or between the Japanese and foreigners in general.

This view of bicultural Nikkeijin as valuable human resources is supported by research in social psychology. In social psychology, Leung and Chiu (2011) found that biculturals are effective intercultural communicators. Effective intercultural communication requires nuanced understanding of cultural differences and discriminative application of cultural knowledge to guide interactions in different cultural contexts. The following comment from an interviewee in the present study, Ana, shows understanding of a cultural difference in Japan, Canada and Brazil. The Japanese have conformist tendencies, unlike Canadians and Brazilians:

'In Canada, I realised that we don't have to follow the same thing (rule) like in, what we have to do in Japan. You know? ... I know that in Japan it's very strict, but I think it's also, it's true (correct), what they are doing is... For example, in Brazil, we throw garbage everywhere. And in Japan, no, we cannot do this, so we... It's not a rule but it’s not something that I will do. You know? ... Because I think Japan is very correct in everything, so...' 
Ana also notices a difference between how the Japanese and Canadians listen to foreigners:

'Like for example, in Japan, when you order something and then you have to talk. And they (the Japanese employees) are different. (They think) 'OK, they're foreigners, so...' They stand back a little bit. But in Canada, I didn't see this difference. They're trying to understand what you have to say.'

Multicultural experiences offer opportunities for intercultural learning, and is positively correlated with effective intercultural communication because nuanced understanding of cross-cultural differences which leads to discriminative application of cultural knowledge in cultural interactions can be acquired in these experiences. (Leung and Chiu, 2011) Through immersion in multiple cultures, multicultural individuals acquire refined knowledge regarding what people in different cultures know, believe in, prefer and value. If they customise the contents and styles of their communications based on their nuanced understanding of cultural differences in knowledge, beliefs, preferences and values, they would be effective when communicating with people from different cultural backgrounds. Therefore, individuals with rich, multicultural experiences, such as the Nikkeijin, would possess nuanced knowledge of cultural differences and be able to use such knowledge discriminatively to guide interactions in different cultural contexts. They have more flexibility in responding to specific demands for culturally appropriate behaviours in intercultural contexts and their behavioural accommodation would lead to effective intercultural communication. Ana feels that she would have an advantage over (monocultural) Japanese in empathising with foreigners in Japan:

'Because the foreigner who's coming to Japan, they don't know how to live in Japan. And because I've experienced this in other countries, I know how they feel. And probably Japanese, they won't understand, because they're Japanese and because maybe, because their experience... And also because that it's in Japan, it's their country.'

\section{Concluding remarks}

At the time of the interviews, two interviewees, Matheus and Fernanda (both pseudonyms), who have completed their university education, had made plans to leave Japan for Brazil, citing disappointment with life of the Nikkeijin in Japan as the reason. Matheus felt that the Japanese are not open-minded enough to embrace foreigners, especially the Nikkeijin, and recognise their contribution. Fernanda feels that in Japan the Nikkeijin will always be confined to the four walls of factories. It is Japan's loss that these two highly-educated, bicultural and trilingual Nikkeijin who have so much potential to contribute to Japan, are leaving the country.

The Nikkeijin work in the automobile and electronics industries and help to maintain their competitiveness in the world but because of the unfavourable terms of their employment, they are trapped in their working-class socio-economic status. One way to help them achieve mobility would be to provide more support for their children's education so that more young Nikkeijin further their education beyond junior high school and high school. Based on what this paper has presented, that bicultural Nikkeijin are in fact valuable human resources with great potential to contribute to Japan, there is more justification than ever for Japan to invest in the Nikkeijin's education.

Many international students from all over the world have successfully applied for Japan Student Services Organization (JASSO) scholarships and benefitted from a period of sponsored study in Japan. The Nikkeijin are eligible to apply for JASSO scholarships but relatively few have been successful. Since public universities are harder to enter and many Nikkei parents cannot afford the fees of private universities, relaxing the stringent criteria for these scholarships for Nikkeijin who want to further their education and publicising their availability would be helpful.

An improvement in the general awareness of the Nikkeijin's middle-class background in Brazil and Peru, their circumstances in Japan and their role in maintaining Japan's competitiveness in the automobile and electronics industry may help eradicate Japanese prejudice and improve the lives of the Nikkeijin in Japan. It is also important to publicise discussions of Nikkei young people's potential to contribute to the country and their advantage as biculturals.

\section{Notes}

1. The socio-economic crisis of the 1980s and 1990s led to massive social inequalities, rampant crime and violence, which motivated many Brazilians to emigrate. Large social inequalities persist to the present day and many continue to leave the country to escape continuing violence and crime. (Rocha, 2014)

2. In 2000, the Brazilian Ministry of Education ratified an edict that ensured that children graduating with credits 
from authorised Brazilian schools in Japan would hold the same qualifications as their counterparts in Brazil. (Green, 2013)

\section{References}

Brannen, M. Y. and Thomas, D. C. (2010). International Journal of Cross Cultural Management 10 (1), 5-16. http://dx.doi.org/10.1177/1470595809359580

Brannen, M. Y., Garcia, D. and Thomas, D. C. (2009). Biculturals as natural bridges for intercultural communication and collaboration. Proceedings of the 2009 International Workshop on Intercultural Collaboration, pp. 207-210.

Chiavacci, D. (2014). Indispensable future workforce or internal security threat? Securing Japan's future and immigration. In W. Vosse, R. Drifte and V. Blechinger-Talcott (Eds.), Governing Insecurity in Japan: The Domestic Discourse and Policy Response (pp. 115-140). London: Routledge.

Green, P. (2013). Education, employment and household dynamics: Brazilian migrants in Japan. Ethnography and Education, 8(3), 273-285. http://dx.doi.org/10.1080/17457823.2013.792680

Green, P. (2010). Generation, family and migration: Young Brazilian factory workers in Japan. Ethnography, 11(4), 515-532.

Hein, P. (2012). Does ethnic origin determine integration success? A comparison of immigration policies in Germany and Japan. Asian Ethnicity, 13(2), 161-185. http://dx.doi.org/10.1080/14631369.2012.625709

Hill, M. R. (1993). Archival Strategies and Techniques. Newbury Park, CA: Sage Publications.

Kibe, T. (2014). Can tabunkakyosei be a public philosophy of integration? Immigration, citizenship and multiculturalism in Japan. In W. Vosse, R. Drifte and V. Blechinger-Talcott (Eds.), Governing Insecurity in Japan: The Domestic Discourse and Policy Response (pp. 71-91). London: Routledge.

Leung, A. K.-Y. and Chiu, C.-Y. (2011). Multicultural experiences and intercultural communication. In A. K.-Y. Leung, C.-Y. Chiu and Y.-Y. Hong (Eds.), Cultural Process: A Social Psychological Perspective (pp. 242-262). Cambridge: Cambridge University Press.

Liu-Farrer, G. (2012). Ambiguous concepts and unintended consequences: rethinking skilled migration in view of Chinese migrants' economic outcomes in Japan. Asien, 124, 159-179.

Liu-Farrer, G. (2011). Making careers in the occupational niche: Chinese students in corporate Japan's transnational business. Journal of Ethnic and Migration Studies, 37(5), 785-803. http://dx.doi.org/10.1080/1369183X.2011.559718

McCulloch, G. (2004). Documentary Research in Education, History and the Social Sciences. London: Routledge Falmer.

Morita, L. (2015). Some manifestations of Japanese exclusionism. Sage Open 5 (3). http://dx.doi.org/10.1177/2158244015600036

Oda, E. (2010). Family narratives and transforming identities: Three generations of Japanese Brazilians living between Brazil, Japan and beyond. Social Identities, 16(6), 775-790. http://dx.doi.org/10.1080/13504630.2010.524784

Ogawa, N. (2011). Population aging and immigration in Japan. Asian and Pacific Migration Journal, 20(2), 133-167. http://dx.doi.org/10.1177/011719681102000202

Rocha, C. (2014). Triangular Circulation: Japanese Brazilians on the move between Japan, Australia and Brazil. Journal of Intercultural Studies, 35(5), 493-512. http://dx.doi.org/10.1080/07256868.2014.944109

Takenoshita, H. (2015). Social capital and mental health among Brazilian immigrants in Japan. International Journal of Japanese Sociology, 24, 48-64. http://dx.doi.org/10.1111/ijjs.12036

Takenoshita, H. (2013). Labour market flexibilisation and the disadvantages of immigrant employment: Japanese-Brazilian immigrants in Japan. Journal of Ethnic and Migration Studies, 39(7), 1177-1195. http://dx.doi.org/10.1080/1369183X.2013.778140

Takenoshita, H., Chitose, Y., Ikegami, S., \& Ishikawa, E. A. (2014). Segmented assimilation, transnationalism, and educational attainment of Brazilian migrant children in Japan. International Migration, 52(2), 84-99. http://dx.doi.org/10.1111/imig.12057 
Tsuda, T. (2011). When human capital does not matter: Local contexts of reception and immigrant wages in Japan. GeoJournal, 76, 641-659. http://dx.doi.org/10.1007/s10708-009-9315-4

Tsuda, T. (2009). Japanese-Brazilian ethnic return migration and the making of Japan's newest immigrant minority. In M. Weiner (Ed.), Japan's Minorities: The Illusion of Homogeneity (pp. 206-227). London: Routledge.

Tsuda, T. (2003). Strangers in the Ethnic Homeland: Japanese Brazilians Return Migration in Transnational Perspective. New York, NY: Columbia University Press.

Vaipae, S. S. (2001). Language minority students in Japanese public schools. In M. G. Noguchi and S. Fotos (Eds.), Studies in Japanese Bilingualism (pp. 184-233). Clevedon: Multilingual Matters.

Vogt, G. (2015). Foreign workers in Japan. In J. Babb (Ed.), The Sage Handbook of Modern Japanese Studies (pp. 567-582). London: Sage.

Ziguras, C. and Law, S.-F. (2006). Recruiting international students as skilled migrants: The global 'skills race' as viewed from Australia and Malaysia. Globalisation, Societies and Education, 4(1), 59-76. http://dx.doi.org/10.1080/14767720600555087 